\title{
Problems and Prospect of Folk Media Usage for Agricultural Extension Service Delivery in Benue State, Nigeria
}

\author{
S.Daudu \\ Department of Agricultural Extension \& Communication, University of Agriculture, \\ Makurdi, Nigeria
}

KEYWORDS Folk Media. Problems. Relative Usage. Prospect

\begin{abstract}
The study investigated the problems and prospect of folk media usage for agricultural extension service delivery in Benue State. A total of 100 respondents were selected using a simple random sampling technique. The collected data were analyzed using percentage, frequency and mean. The result of the analysis showed that the types of folk media used in descending order of their usefulness were folk songs, friends,/Association, folk puppet theatre and drama. While the most frequently used folk media were folk dance, folk songs, friends/Association, and groups/Association. The result further indicated that the three most frequently mentioned problems associated with folk media usage were lack of fidelity, costly to organize and poor clarity. It was therefore recommended that policy makers and practitioners choose appropriate folk media for use considering the level of usefulness and frequency of use. Secondly in order to surmount the problem of lack of fidelity farmers should be involved in the packaging of messages and respected members of the community selected as actors to deliver the messages. Also frequently used and useful folk media which are relevant and cost effective could be used to reduce cost of organizing folk media usage. Also solo singers could be used instead of dance groups to reduce cost. Finally, development agencies and practitioners could adopt folk media usage for agricultural information dissemination because it has great prospect in Benue State.
\end{abstract}

\section{INTRODUCTION}

Folk media or local and traditional communication systems refers to all organized processes of production and exchange of information managed by rural communities. These also include traditional theatre or drama, masks and puppet performances, tales, proverbs, riddles and songs. They are cultural and endogenous responses to different community needs for information, education, social protest and entertainment (Chiovoloni 2004).

The folk media is a communication vehicle for promoting and improving dialogue which the common people or rural farmers employ to deliver their messages (Zwaal 2000). It is something related to the people's past, present and future providing them with a glimpse of reality that results in education. It is the media for the people, the mass of people most deprived of specific massages (Fernandez 1996). These messages embrace a wide range of traditional communication channels which include story telling, theatre, folk songs, dance and folk puppetry (Fernandez 1996; Van Den Ban and Hawkins 1996). Folk patterns of communication and social interaction in Africa are those ways of passing messages which are original to the African people as opposed to the modern communication methods (Kombol 2002). Folk media, therefore is an interactive and participatory traditional communication media, despite its crudeness, albeit sophistication, rural people use to ensure dialogue.

Folk media including tradition forms of entertainment can be inexpensive media (Adebayo 1997). They are used primarily for entertainment in the rural areas and can be adapted to transmit messages about agricultural practices and ideas (Obinne 1994). Folk media are interactive and participatory (Adoyo 2004). For instance, drama as a traditional means of information allows different possible endings by encouraging audience participation which is aimed at changing the behavior of participants of such means of communication (Panelist 2000; Adoyo 2004).

Folk media can be delineated into four media spectra in a communication continuum in Nigeria, namely folk, elite, popular and mass with the folk media being central to others (Nkala 1990). According to Valbuena (1993) folk media is entertainment communication because its performance such as story telling, theatre shows, puppet shows and drama could facilitate development of agricultural extension programmes through the rapid diffusion of new technologies and its 
demonstrational values could serve as an effective vehicle for transmission of social messages.

A symbiotic relationship exists between communication and development. It is in realization of the important role of communication in rural development that the Food and Agricultural Organization (FAO) recommended that development support communication should be an integral part of any development initiative so that the appropriate medium or media to effectively reach the target population could be specified (Yahaya 2002).

Dialogue is the essence of any work in communication for development. Folk media has quickly been recognized as one way of ensuring such a dialogue (Kamlongera 1995; Van Den Stichele 2000).

Drama (role-playing), town criers and other traditional media are not adequately used in extension in Nigeria. Where they are used on pilot basis, they have proved effective, less expensive and are liked by people (FMANRRD 1989; Adebayo 1997; Chiovoloni 2004). According to Chiovoloni (2004) and Hiemstra et al. (2004) for sustainable development of Agriculture there is a need for close collaboration between development agents and traditional and new rural communicators to revive or strengthen the traditional communication system for making optimal use of its interactive power to stimulate peoples participation.

Despite the existence and use of folk media in agricultural information dissemination in the rural areas of Benue State there is lack of empirical studies carried out to assess, characterize and validate the problems and prospect of folk media usage for extension service delivery in Benue State. This study sought to fill this gap. What are the types of folk media used in communicating agricultural extension massages in Benue State? What is the relative usage of these folk media in communicating agricultural messages? What are the farmers' perception of the usefulness of there media in information dissemination? What are the problems associated with the use of folk media?

The purpose of this study was to assess the prospect and problems of the use of folk media in agricultural extension service delivery in Benue State. The specific objectives of the study were to: identify the types and usefulness of these folk media in Benue State; determine the relative usage of these folk media for accessing agricultural information, and identify the problems associated with the use of folk media for communicating agricultural information.

\section{LITERATURE REVIEW}

Extension services are essentially communicative (Akeredolu and Ajayi 1995; Adebayo and Adedoyin 2005). Communication is a key process in information dissemination in natural resource management (Adebayo and Adedoyin 2005).

Many rural people utilize folk media for communication of cultural messages. In African context sensitive information is never passed in a straight forward manner but through songs, dances and plays using proverbs and poems: the mirrors technique. As a result listeners decide to do something to change the situation they find themselves in (Adoyo 2004).

Valbuena (1993) reported that in southern Singapore folk performance has helped rural farmer in their development process through the various strategies used in the production, storage, preservation and even marketing of rice. Van Den Ban and Hawkins (1996) reported that Wayang Kulit or shadow puppets have been used to promote agricultural innovations in Java. They further reported that a Brazilian extension service commissioned a popular singer to write and perform folk songs, which incorporated technical messages about fertilizer use.

Azeez and Jimo (2003) examined the traditional media use in Forest conservation support communication (FCS) among local residents in protected areas in south western Nigeria and observed that most $(88.75 \%)$ of the respondent perceived trado communication as complementing other information sources and all respondents agreed that trado communication was useful.

In Benue State the use of fertilizer and tractor was promoted through traditional songs and kwagh-hir puppet theatre in Tiv land. The Ochahuhu dance was also used in Otukpo Local Government Area to promote herbicide usage (Benue State Government 2002).

\section{CONCEPTUAL MODEL}

In order to effectively reach the rural people an appropriate communication medium needs to be selected. Folk media has been widely accepted by scholars and practitioners as appropriate in this regard (Kamlongera 2000; Chiovolono 2004; 
Adoyo 2004). This is because rural people have an ingenious way of contributing sensitive information not in a straight forward and manner, but through songs, dance and plays using poems and proverbs (Adoyo 2004). Consequently folk media are interactive cultural resources which are used to pass messages among rural people.

Ng'ombe (2000) conceptualized folk media communication using the s-r model assuming that participants will play their roles in the traditional source-receiver communication model. Secondly rural people have a communication system and that the extension agent will be willing to accept the farmer as a source on information and knowledge.

Often music or theatre are more fun and easier to remember and woven in the muscle memory and literally locked in the body fabric (Hiemstra et al. 2004). To achieve this interactive and participatory quality folk media messages must be appropriately packaged and applied for desired impact (Adoyo 2004). The framework for folk media usage is represented schematically as shown in figure 1 .

\section{METHODOLOGY}

Benue State, the food basket of the nation, lies in the central agro-ecological region of Nigeria. It is located on Longitude $6^{0} 35^{\prime} \mathrm{E}$ to $10^{\circ} \mathrm{E}$ and latitude $60^{\circ} 30^{\prime} \mathrm{N}$ to $8^{\circ} 10^{\prime} \mathrm{N}$ of the equator. According to the 1991 national census it has a population of 2,780,359 and a total landmass of 3095 square kilometers (Benue State Government 2002).

Majority of the people are arable farmers while fishing is the primary occupation of most of the riverine inhabitants. Politically the state is divided into 23 local government areas. The major ethnic groups are Tiv located in the northern and central zones while the Idoma and Igede are in the eastern zone. Major food crops include yam, rice, beans cassava, soyabean, beniseed (sesame), maize, sorghum millet, tomatoes, oil palm and citrus. Livestock kept include poultry, goats, sheep, pigs and cows.

The target population of the study is farmers in Benue State. Two local government areas, Gboko (Northern zone, Tiv) and Otukpo (eastern zone, Idoma) were purposively selected for the study because of their fame in Kwagh-hir puppet theatre, traditional songs and dances.

Gboko Local Government Area consists of 17 council wards. Out of these five wards were randomly selected. These were Yandev, Gboko East, Mbatser, Mbakwen and Mbadim. Ten farmers were randomly selected in each ward and interviewed using an interview schedule.

Otukpo local government area consists of 13 council wards. Five wards were randomly selected, namely Adokaicho, Otobi, Ogbojuehaji, Entekpa and Okete. Ten farmers were randomly selected from each ward and interviewed.

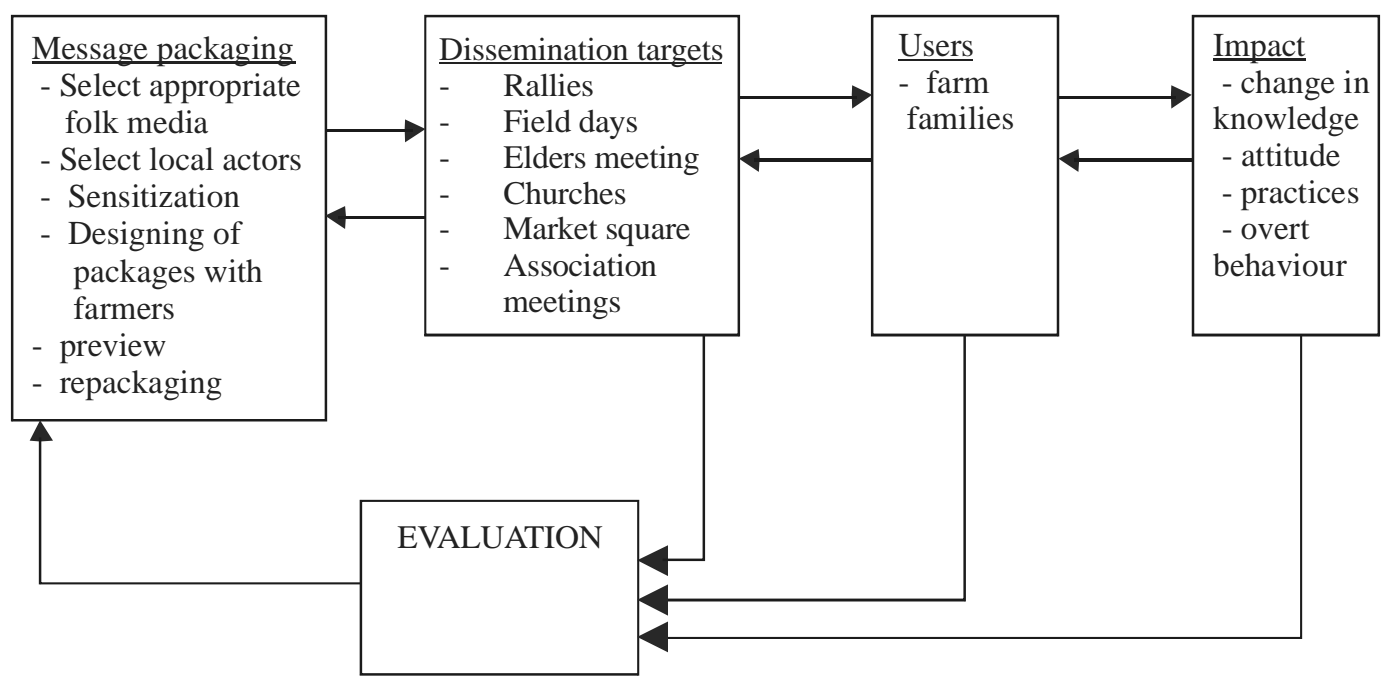

Fig. 1. A conceptual framework for folk media usage 
Thus 50 farmers were selected from each LGA by random sampling method. A total sample of 100 respondents were selected.

Primary data for this study was collected using a validated interview schedule in the form of structured and unstructured questionnaire. These were used to obtain information in line with the objectives of the study.

To identify the types of folk media used in Benue State for dissemination of agricultural information respondents were asked to name the types of folk media used in their locality in order of their usefulness. To determine the relative usage of each medium, a three point likert scale was similarly used. To ascertain the problems associated with the use of folk media for agricultural information disseminating farmers were asked to name any six problems they could remember.

\section{ANALYSIS OF DATA}

Objective 1: Percentage, frequency and ranking was used to identify the types of folk media and their usefulness. Objectives 2: frequency, percentage and mean score were used to determine the relative usage (frequency of use) of the folk media using likert scale. To determine the relative usage level of each folk media a three point likert-type scale with responses ranging from "not frequent", "moderately frequent" and "highly frequent" and scaled 1 to 3 were adopted to get a value of 6 which was later divided by 3 to get a mean score of 2 . Then respondents' mean scores were obtained on each response item, such that any one higher or equal to 2 was regarded as frequently used, while any mean response lower than 2 was regarded as not frequently used, and Objective 3: Frequency and percentage were used to analyze respondents' perception of problems associated with folk media usage.

\section{RESULTSAND DISCUSSION}

\section{Types of Folk Media}

Data on table 1 reveal that the types of folk media in order of usefulness as mentioned by respondents were: Folk Songs $(87 \%)$, Friends/ Relations (77\%), Folk dances (75\%), Town crier (68\%), Groups/Association (52\%), Folk Puppet Theatre (37\%), and Drama (21\%). Farmers regard folk songs, friends/relations folk dances, town crier and Group/Association as useful media.
Table 1: Distribution of respondents by type of folk media used for agricultural information dissemination

\begin{tabular}{|c|c|c|c|c|}
\hline $\begin{array}{l}\text { S. } \\
\text { No. }\end{array}$ & $\begin{array}{l}\text { Types of folk } \\
\text { media }\end{array}$ & $\begin{array}{c}\text { Fre- } \\
\text { quency }\end{array}$ & $\begin{array}{l}\text { Percent- } \\
\text { age }\end{array}$ & $\begin{array}{l}\text { Ranking in } \\
\text { order of } \\
\text { usefulness }\end{array}$ \\
\hline 1. & Folk songs & 87 & 87 & 1 \\
\hline 2. & Friends/Association & 77 & 77 & 2 \\
\hline 3 . & Folk dance & 75 & 75 & 3 \\
\hline 4. & Town Crier & 68 & 68 & 4 \\
\hline 5. & Groups/Association & 52 & 52 & 5 \\
\hline 6. & Folk puppet theatre & 37 & 37 & 6 \\
\hline 7. & Drama & 21 & 21 & 7 \\
\hline
\end{tabular}

*Multiple responses recorded.

Source: Field Survey, 2006

This confirms that rural people have ingenious way of contributing sensitive information through songs, dance and plays (Adoyo 2004). This may not be unconnected with Benue people's traditional interest in cultural activities, the state being one of the rural states in Nigeria.

\section{Relative Usage of Folk Media}

Entries on table 2 show that majority of the respondents indicated frequent use of folk dances $(x=2.45)$, folk songs $(x=2.30)$, friends/ Relations $(\mathrm{x}=2.18)$ and Groups/Association $(x=2.02)$. Therefore, puppet theatre, town crier and drama are not frequently used while folk dance, friends/association and groups/ association are frequently used in the State. This is probably because folk media is entertainment media (Adebayo 1997). Benue people love ceremonies and entertainment and therefore more frequently use associative and the ceremonial folk media.

Table 2: Distribution of respondents by frequency of folk media usage

\begin{tabular}{lll}
\hline S. No. & Folk media & Mean score $(x)$ \\
\hline 1 & Town crier & 1.94 \\
2 & Folk dance & $2.45^{*}$ \\
3 & Folk songs & $2.30^{*}$ \\
4 & Folk puppet theatre & 1.32 \\
5 & Drama & 1.28 \\
6 & Friends/Association & $2.18^{*}$ \\
7 & Groups/Association & $2.02^{*}$ \\
\hline
\end{tabular}

*frequent

Source: Field Survey, 2006

\section{Problems Associated With Folk Media Usage}

Table 3 shows that the three most frequently mentioned problem perceived by respondents 
was lack of fidelity (74\%), followed by Expensive to organize $(60 \%)$, clarity $(24 \%)$. To use folk media effectively the major problems of lack of fidelity, high organizing expenses and poor clarity must be tackled. Not withstanding, the problems highlighted folk media have proved to be effective,less expensive and liked by people (FMAWRRD 1989; Adebayo 1997; Chiovoloni, 2004). There is probably the need for close collaboration between development agents, traditional and new Rural communicators to revive or strengthen the traditional communication system by reducing the major problems highlighted to stimulate people's participation (Chiovoloni 2004 and Hiemeftra et al. 2004)

Table 3: Distribution of respondents by perceived problems of folk media usage.

\begin{tabular}{|c|c|c|c|}
\hline $\begin{array}{l}S . \\
\text { No. }\end{array}$ & $\begin{array}{l}\text { Problems associated } \\
\text { with folk media }\end{array}$ & Frequency & Percentage \\
\hline 1. & Lack of fidelity & 74 & 74 \\
\hline 2 . & Costly to organize & 60 & 60 \\
\hline 3. & Poor clarity & 24 & 24 \\
\hline 4. & Limited coverage & 18 & 18 \\
\hline 5. & Time inconvenience & 13 & 13 \\
\hline 6. & Traditional Restriction & 5 & 5 \\
\hline 7. & Poor feedback & 3 & 3 \\
\hline
\end{tabular}

*Multiple responses recorded

Source: Field Survey, 2006

\section{CONCLUSIONAND RECOMMENDATIONS}

As a result of the major findings of the study the following conclusion was drawn.

The types of folk media identified in the study area in descending order of usefulness were folk songs, friends/relations, folk dances town crier, groups/associations and folk puppet theatre. Also the frequently used folk media in descending order were folk dances, folk songs, friends/relation and groups/associations, while, the three most commonly mentioned problems associated with the use of folk media were lack of fidelity cost of organizing and poor clarity. Consequently, in order to use folk media effectively among farmers in Benue State these problems must he considered.

In view of this, the following recommendations were made:

(i) In communicating agricultural information of farmers using folk media the types of media farmer consider useful in descending order are folk songs, friends/relations, folk dance, town crier, groups/association and folk puppet theatre.
Similarly in descending order of frequency of use of these media are folk dance, folk songs, friends/ relations and groups/associations. Consequently policy makers and practitioners may choose the appropriate media considering the level of usefulness and frequency of use to ensure adequate impact.

(ii) The major problems associated with the use of folk media were lack of fidelity, cost of organizing and lack of clarity. In order to surmount the problem of lack of fidelity it is recommended that farmers should be involved in the packaging of messages and respected members selected as actors to deliver these messages. Similarly cost of organizing folk media messages could be reduced by making use of the knowledge of the local folk media problems, frequency of use and usefulness of these types of folk media to ensure that the chosen folk media are cheaper and cost effective. For instance folk songs could involve a solo folk singer instead of using folk dance group to reduce the number of actors involved and hence cost. While message clarity can be enhanced by using the stopdiscuss approach by stopping at any point of folk media message presentation to explain unclear points.

(iii) Agencies interested in rural development especially agricultural information dissemination should note that there is certainly a good prospect for folk media usage for extension service delivery in Benue State.

\section{REFERENCES}

Adebayo K 1997. Communication in Agriculture. Abeokuta: Integrity Prints.

Adebayo K, Adedoyin SF 2005. Communication and advocacy strategies in extension. In: SF Adedoyin (Eds.): Agricultural Extension in Nigeria. Ilorin, Nigeria: AESON C/on ARMTI.

Adoyo F 2004. The Mirror Technique in rural extension. Ileia magazine April 28, 2004, pp. 1-4.

Akeredolu MO, Ajayi A 1995. Communication issues in Extension: Informedness and explanatory ability of village extension agents in Lagos state. In: SF Adedoyin, I Aihonsu (Eds.): Sustainable Development in Rural Nigeria. Proceedings of the eight annual conference of the Nigerian Rural Sociological Society, pp. 291-301.

Azeez IO, Jimo SO 2003. Traditional medial use in Forest conservation support communication (FCSC) among local residents in protected areas in South Western, Nigeria. Journal of Environmental Extension, 4: 19-30.

Berue State Government: Diary 2002. Nigeria. 
Chiovoloni M 2004. The interactive power of local and traditional communication systems. Ileia Magazine. April 28, 2004, pp. 1-4.

Federal Ministry of Agriculture, Water Resources and Rural Development, FMAWRRD 1989. A Perspective Plan for Agricultural Development in Nigeria, 1990-2005. Abuja: FMAWRRD.

Fernandez DG 1996. Essay on Phillipine Theatre History. Ataneale: Manilla University Press.

Hiemstra W, Bruinsma W, Witteveen L 2004. A new look at information. ILEIA Magazine, April 28, 2004, pp.1-4.

Kamlongera C 2000. Folk Media in Communication for Development: A note In: P Van Der Stichele (Artrcle Editor) Folk And Traditional Media for Rural Development. A workshop held in Malawis Liiongwe, 23 August - 3 September 1999http:// www.yahoomail.com Retrieved April 28, 2005.

Kombol MA 2002. African Communication System: An Introduction. Makurdi Nigeria: Satrix Books.

Ng'ombe JL 2000. The communication model and folk media in development: I In: P Van Der Stichele (Article Editor) Folk and Traditional Media for Rural Development. A workshop held in Malawis Liiongwe, 23 August - 3 September 1999 http:// www.yahoomail.com Retrieved April 28, 2005.

Nkala MO 1990. Traditional channel of communication and Rural development policy implementation. The neglected symbiosis. In: IE Nwosu (Ed.): Mass Communication and National Development. Negeria: Aba Frontier Publishers, P. 60.

Obinne C 1994. Fundamentals of Agricultural Extension. Enugu, Nigeria: ABIC Publishers.

Panelist LD 2000. Entertainment Education. Conference Proceedings. Baltimore: John Hopkins University.

Valbuena VT 1993. Weaving Together Folk Media and Mass Media. Development Communication Report No. 74, 1991/3. Singapore.

Van dan Ban AW, Hawkins HI 1996. Agricultural Extension. $2^{\text {nd }}$ Edition, Essex: Longman

Van der Stichele P 2000. Folk and traditional media for rural development: A workshop held in Malawi. http://www.yahoomail.com Retrieved April 28, 2005 .

Yahaya MK 2002. Gender and communication variable in Agricultural information Dissemination in Two -Agro-Ecological Zones of Nigeria. Research Monograph, University of Ibadan, Ibadan. Ibadan: Corporate Graphics Limited.

Zwaal PN 2000. Story Telling as a Vehicle for Improving Inter-cultural Dialogue: Thesis on environmental conservation in Cameroon. Retrieved May 30 2005 . 